\title{
Psychostimulants Induce Low-Frequency Oscillations in the Firing Activity of Dopamine Neurons
}

\author{
Wei-Xing Shi*,', Chen-Lun Pun' and Yan Zhou' \\ 'Neuropsychopharmacological Research Unit, Department of Psychiatry, Yale University School of Medicine, New Haven, CT, USA
}

\begin{abstract}
The reinforcing properties of psychostimulants depend critically on their effects on dopamine (DA) neurons in the ventral tegmental area (VTA). Using in vivo single unit recording in rats and spectral analysis, this study presents evidence for a new, non-DA-mediated effect of psychostimulants on VTA DA neurons. Thus, as previously observed with D-amphetamine, all psychostimulants tested, including cocaine, methamphetamine, and methylphenidate, had two opposing effects on firing rate of DA neurons: a DA-mediated inhibition and a nonDA-mediated excitation. The latter effect was normally masked by the DA-mediated inhibition and was revealed when the inhibition was blocked by a DA antagonist. Using spectral analysis, this study further showed that during psychostimulant-induced excitation, DA cells exhibited not only an increase in firing rate and bursting but also a low-frequency rhythmic oscillation $(0.5-1.5 \mathrm{~Hz})$ in their firing activity. The oscillatory response was unique to psychostimulants since it was not observed with the GABA $A_{A}$ agonist muscimol, which also increased DA cell firing, and not mimicked by the nonpsychostimulant DA agonist L-dopa. Results further suggest that the effect requires activation of adrenergic $\alpha_{1}$ receptors and depends on intact forebrain inputs to DA neurons. Further understanding of this novel effect may provide important insights into both the mechanism of action of psychostimulants and the neuronal circuitry that controls the activity of DA neurons in the brain.

Neuropsychopharmacology (2004) 29, 2 I60-2 I67, advance online publication, I4 July 2004; doi: I 0. I 038/sj.npp. 1300534
\end{abstract}

Keywords: psychostimulant; norepinephrine; ventral tegmental area; bursting; oscillation; spectral analysis

\section{INTRODUCTION}

Amphetamine-like psychostimulants have multiple effects on dopamine (DA) neurons. By interacting with the DA transporter (DAT), these drugs are known to cause DA release and/or to block DA reuptake. Owing to the presence of negative feedback mechanisms, the increase in DA release also leads to an inhibition of firing of DA neurons (Bunney et al, 1973b; Einhorn et al, 1988; Shi et al, 2000a). This feedback inhibition alters following repeated psychostimulant administration and has, thus, been suggested to play a role in behaviors associated with psychostimulant abuse (Ellinwood and Lee, 1983; Kamata and Rebec, 1983; White and Wang, 1984; Henry et al, 1989; Wolf et al, 1993). We have recently shown that when the DA-mediated feedback inhibition is blocked by a DA antagonist such as raclopride, D-amphetamine, instead of producing no effect, powerfully excites DA cells (Shi et al, 2000b). Results further

*Correspondence: Dr W-X Shi, Neuropsychopharmacological Research Unit, Department of Psychiatry, Yale University School of Medicine, 300 George Street, Room 8300C, New Haven, CT 065।I, USA, Tel: + I 203785 4507, Fax: + I 203785 45।0, E-mail: wei-xing.shi@yale.edu

Received 7 January 2004; revised 6 May 2004; accepted I 4 June 2004 Online publication: 24 June 2004 at http://www.acnp.org/citations/ Npp062404040 I0/default.pdf suggest that the effect is, in part, due to the activation of adrenergic $\alpha_{1}$ receptors.

Although the excitatory effect of D-amphetamine is normally masked by the dominant DA-mediated inhibition, in nonanesthetized rats chronically treated with D-amphetamine, half of DA neurons recorded in the ventral tegmental area (VTA) have been shown to be excited by an acute injection of D-amphetamine (Kamata and Rebec, 1984), suggesting that the excitatory effect of D-amphetamine may become dominant in some VTA DA neurons following repeated administration. A similar situation may occur during early development when negative feedback mechanisms of DA neurons are not fully developed (Trent et al, 1991) and in DAT-knockout mice in which DAmediated feedback mechanisms are desensitized (Jones et al, 1999). The $\alpha 1$-mediated excitation may also provide part of the explanation as to why D-amphetamine remains effective in increasing DA release in DAT-knockout mice (Carboni et al, 2001), and why the drug is less effective in producing the same effect in $\alpha_{1 \mathrm{~b}}$ receptor-knockout mice (Auclair et al, 2002).

The present study was initially designed to examine whether other psychostimulants such as cocaine mimic the excitatory effect of D-amphetamine. In the course of data analysis, we noticed that the pattern of spike distribution induced by cocaine was not predicted by an increase in firing rate. Furthermore, the $\mathrm{GABA}_{\mathrm{A}}$ agonist muscimol, 
which also increased DA cell firing (Walters and Lakoski, 1978; Grace and Bunney, 1979; Waszczak and Walters, 1980) and DA release (Xi and Stein, 1998), produced a pattern very different from that induced by cocaine. Here, we provide evidence that cocaine not only increases firing rate and bursting but also induces a slow oscillation in DA neurons. Muscimol, on the other hand, suppresses the slow oscillation. Some results have been previously presented in abstract form (Shi et al, 2003).

\section{MATERIALS AND METHODS}

\section{Single Unit Recordings In Vivo}

All procedures were performed in accordance with protocols approved by the Yale Animal Care and Use Committee. Male Sprague-Dawley rats, weighing between 250 and $400 \mathrm{~g}$, were anesthetized with chloral hydrate $(400 \mathrm{mg} / \mathrm{kg}$, i.p., with supplemental doses administered via a lateral tail vein). DA neurons in the VTA were identified and recorded extracellularly using techniques described previously (Bunney et al, 1973b; Grace and Bunney, 1983; Shi et al, 2000b). Interspike intervals (ISIs) were collected on line via an interface (Lab-PC ${ }^{+}$, National Instrument, Austin, Taxes) to a PC computer using software written in LabView for Windows. In a subset of animals, ipsilateral forebrain hemisections ( $4 \mathrm{~mm}$ posterior to bregma) were made $30 \mathrm{~min}$ before beginning of recording (Shi et al, 2000a). Only one cell was studied in each rat.

\section{Drugs}

Drugs used in this study were cocaine hydrochloride, D-amphetamine sulfate, (+)-methamphetamine hydrochloride, methylphenidate hydrochloride, L-dopa methyl ester hydrochloride, nisoxetine hydrochloride, $s(-)$-raclopride $(+)$-tartrate, and prazosin hydrochloride. All were purchased from Sigma-RBI (St Louis, MO) and administered intravenously through a lateral tail vein. All doses given refer to the salts. Prazosin was dissolved in $25-30 \%$ poly(ethylene glycol) (PEG, average MW 200) at $2.5 \mathrm{mg} / \mathrm{ml}$. Before injection, the solution was diluted with distilled water so that the final volume of injection was either 0.05 or $0.1 \mathrm{ml}$. All other drugs were dissolved in distilled water.

\section{Data Analysis}

All analyses were performed using Visual Basic macros in Microsoft Excel. The onset of a burst was identified as the concurrence of two spikes with an ISI less than $80 \mathrm{~ms}$ and the termination of a burst was defined as an ISI greater than $160 \mathrm{~ms}$ (Grace and Bunney, 1984). Two approaches were taken to measure firing periodicity of a cell. First, rate histograms were constructed with a bin width of $50 \mathrm{~ms}$. Segments (102.4 s) of the rate histogram were then subjected to the fast Fourier transform (FFT), yielding spectra with a frequency resolution of $0.01 \mathrm{~Hz}$. In the second approach, autocorrelograms were constructed with a bin width of $45 \mathrm{~ms}$ over 2048 bins using autocovariance computed from the same ISI data sets. Following tapering (2.5\% data points on each end using a split-cosine-bell function) and removal of the linear trend, the FFT was performed to yield spectra with a resolution of $0.0109 \mathrm{~Hz}$. Results of the two approaches were qualitatively identical. For simplicity, all spectral data reported in this study, unless noted, were from autocorrelograms.

To help visualize slow changes in rate histograms and autocorrelograms (eg, Figure 2a and b), data were smoothed using the following function:

$$
\begin{array}{ll}
y_{i}=(1-\alpha)^{*} x_{i}+\alpha^{*} x_{i+1} & (\text { for } i=1) \\
y_{i}=(1-\alpha)^{*} x_{i}+\alpha^{*}\left(x_{i-1}+x_{i+1}\right) / 2 & (\text { for } 1<i<\mathrm{N}) \\
y_{i}=(1-\alpha)^{*} x_{i}+\alpha^{*} x_{i-1} & (\text { for } i=N)
\end{array}
$$

where $y_{i}$ is the smoothed value, $x_{i}$ is the original data, $x_{i-1}$ and $x_{i+1}$ are values immediately before and after $x_{i}$, respectively, and $\alpha$ is the smoothing factor $(0<\alpha<1)$. For the purpose of this study, each data series was repeatedly smoothed by a factor of 0.4 for 10 times. The number of repeat serves a role similar to that of window size in a widow smoothing function. Unlike commonly used window functions, however, this method does not introduce rhythmic background noises to the final spectrum. As might be expected, spectra from smoothed data were nearly identical to those from unsmoothed results in the lowfrequency range. However, peaks at high frequencies $(>3 \mathrm{~Hz}$ ) were significantly suppressed. Since we were also interested in oscillations higher than $3 \mathrm{~Hz}$, all spectral results reported in this study were from unsmoothed data.

The statistical significance of an effect of a drug was determined by comparing measures before and after drug injection using ANCOVA followed by a post hoc Tukey test. The covariate was the baseline value obtained prior to the first drug injection. Spectral data were log-transformed before subjected to statistical comparison. All numerical data were expressed as the mean \pm SEM.

\section{RESULTS}

\section{Effects of Cocaine on Spike Distribution of DA Neurons}

D-Amphetamine has been shown to excite DA neurons when the DA-mediated feedback inhibition is blocked (Shi et al, 2000b). To determine whether cocaine mimics the effect, VTA DA neurons were recorded in rats pretreated with the $D_{2 / 3}$ antagonist raclopride $(0.1-0.2 \mathrm{mg} / \mathrm{kg})$. In all cells tested, cocaine $(1 \mathrm{mg} / \mathrm{kg}$ ) increased firing rate (from $4.7 \pm 0.4$ to $6.0 \pm 0.4$ spikes/s, $n=15, p<0.001$, Figure $1 \mathrm{a}$ ).

To monitor continuously changes in firing pattern, instantaneous firing rates (1/ISI) were plotted against time (Figure 1a). Unexpectedly, the increase in firing rate induced by cocaine was associated with an increase in not only short but also long ISIs. Consequently, the variation coefficient of ISIs was significantly increased (from $49.2 \pm 4.8$ to $76.4 \pm 7.1 \%$ of the mean ISI, $n=15$, $p<0.001)$. To determine whether the change is common when a DA neuron is excited, the $\mathrm{GABA}_{\mathrm{A}}$ agonist muscimol was administered. Confirming previous results (Walters and Lakoski, 1978; Grace and Bunney, 1979; Waszczak and Walters, 1980), muscimol $(2 \mathrm{mg} / \mathrm{kg})$ increased firing rate in all DA cells tested (from $4.4 \pm 0.6$ to $5.8 \pm 0.6$ spikes/s, $n=8$, $p<0.001$ ). Unlike cocaine, however, muscimol decreased the variation coefficient of ISIs from $54.4 \pm 3.0$ to $25.3 \pm 5.3 \%(p<0.001$, Figure $1 \mathrm{~b})$. Similar results were obtained when muscimol was given after raclopride 


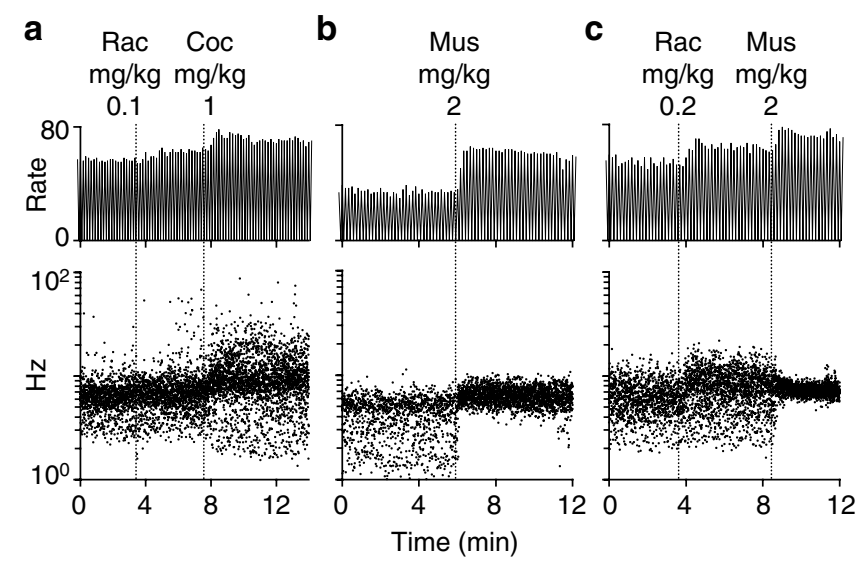

Figure I Different firing patterns induced by cocaine and muscimol. (a) Top: Typical rate histogram showing excitation of a DA neuron induced by cocaine (Coc) given after raclopride (Rac). Bin width: $10 \mathrm{~s}$. Y-axis unit: spikes/IO s. Bottom: plots of instantaneous firing rate (I/ISIs) showing an increase in ISI variation during cocaine-induced excitation. Each dot represents one ISI. (b) Recordings from a different DA cell showing that the $G_{A B A}$ agonist muscimol (Mus) also increased firing rate (top), but it decreased ISI variation (bottom). (c) In another DA cell, muscimol produced similar effects when given after raclopride.

$(0.2 \mathrm{mg} / \mathrm{kg}, n=8$, Figure $1 \mathrm{c})$, suggesting that raclopride used in the cocaine experiments is not directly responsible for different results obtained with cocaine and muscimol.

\section{Effects of Cocaine and Muscimol on Oscillatory Properties of DA Neurons}

An increase in ISI variation indicates an increased irregularity of firing. However, the general pattern of spike distribution induced by cocaine seemed to repeat over time (Figure 1a), suggesting that the large variation in ISIs induced by cocaine may not be entirely random and may contain periodic components. To test this possibility, FFT analysis was performed on rate histograms constructed with a small bin width $(50 \mathrm{~ms}$, Figure $2 \mathrm{a})$ and on autocorrelograms using autocovariances (unstandardized autocorrelation) computed from the same ISI data sets (Figure $2 \mathrm{~b}$ ). The two approaches yielded qualitatively identical results; both showed a large increase by cocaine in the mean power between 0.5 and $1.5 \mathrm{~Hz}\left(P_{\text {Low }}\right.$, Figure $2 \mathrm{a}$ and $\left.\mathrm{b}\right)$. The mean power between 3 and $10 \mathrm{~Hz}\left(P_{\mathrm{High}}\right.$, Figure 3$)$, however, was unaffected, suggesting that cocaine selectively increases the slow oscillation of DA neurons. Muscimol, on the other hand, suppressed the slow $\left(P_{\text {Low }}\right)$ and increased the fast oscillations $\left(P_{\mathrm{High}}\right.$, Figures $2 \mathrm{c}$ and 3$)$.

As shown in Figure 2c, some DA cells exhibited a clear slow oscillation even under baseline conditions. To determine the significance of the activity, we compared $P_{\text {Low }}$ with the mean power of the adjacent frequencies $\left(0-3 \mathrm{~Hz}, P_{0-3 \mathrm{~Hz}}\right)$. In cells tested with cocaine, $P_{\text {Low }}$ was significantly higher than $P_{0-3 \mathrm{~Hz}}$ in one out 15 cells under baseline conditions. After raclopride, the number of cells showing significantly higher $P_{\text {Low }}$ was increased to 3 . Following cocaine, the number was further increased to 9 .

Adrenergic $\alpha_{1}$ receptors have been shown to play a critical role in the excitatory effect of D-amphetamine on DA neurons (Shi et al, 2000b). To test whether they are also
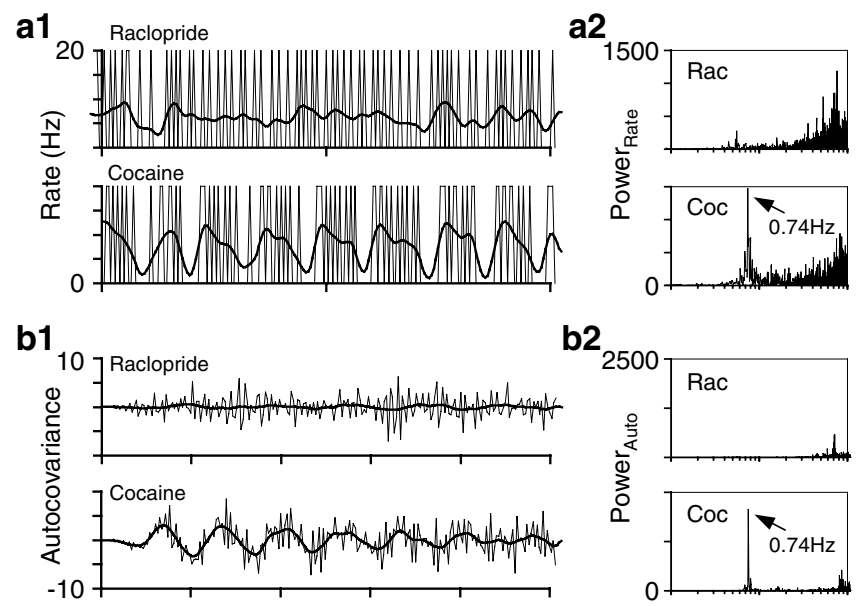

b2

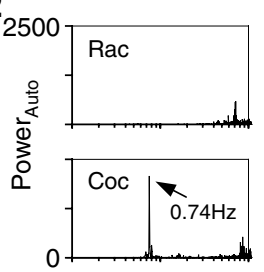

c1

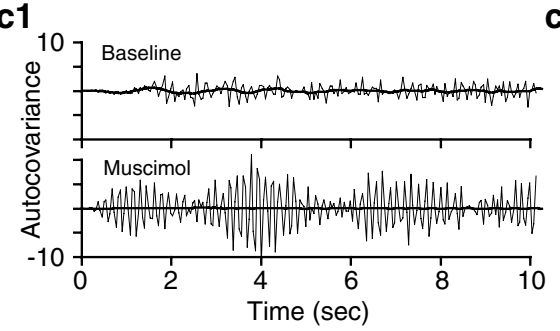

c2

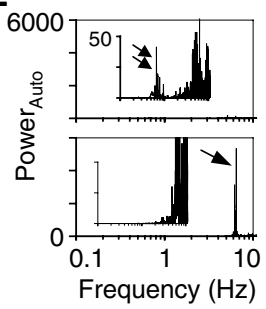

Figure 2 Slow oscillation and effects of cocaine and muscimol. (al) Portions of the rate histogram of the cell shown in Figure I a reconstructed with a bin width of 50 ms (top: after raclopride; bottom: after cocaine). To help visualizing slow changes, data were smoothed and results were shown in thick lines. Note the oscillation in firing after cocaine injection (about seven times per $10 \mathrm{~s}$, that is, $0.7 \mathrm{~Hz}$ ). Y-axis unit: spikes/s. (a2) Spectra computed from the rate histograms. Consistent with the observation in (al), a major peak was detected at $0.74 \mathrm{~Hz}$ after cocaine injection. Y-axis unit: (spikes $/ \mathrm{s})^{2} / \mathrm{Hz}$. (bl) Portions of autocorrelograms (autocovariance) with the linear trend removed and data at the beginning tapered (see Material and methods). Thin and thick lines are the raw and smoothed data, respectively. Y-axis unit: (spikes/s) ${ }^{2}$. (b2) Power spectra of the autocorrelograms showing again a major peak at $0.74 \mathrm{~Hz}$ after cocaine injection. Y-axis unit: (spikes/s) $4 / \mathrm{Hz}$. (cl) Autocorrelograms from the cell shown in Figure Ib. (c2) Power spectra of the autocorrelograms showing a decrease in the low-frequency oscillation $(0.67 \mathrm{~Hz}$, double arrow) and an increase in the high-frequency $(6.43 \mathrm{~Hz}$, single arrow) oscillation by muscimol (Mus). The insets are the same spectra displayed on an expanded $Y$-axis scale to show the presence of the slow oscillation $(0.67 \mathrm{~Hz})$ under baseline conditions (top inset, double arrow) and its suppression by muscimol (bottom inset)

involved in the effect of cocaine, rats were pretreated with the $\alpha 1$ antagonist prazosin $(0.5 \mathrm{mg} / \mathrm{kg}, n=6)$. While having no effect by itself, prazosin prevented cocaine, given after raclopride, from increasing both firing rate and the slow oscillation $\left(P_{\text {Low }}\right.$, Figure 3$)$.

\section{Relations between the Slow Oscillation and Bursting}

Like D-amphetamine (Shi et al, 2000b), cocaine increased bursting of DA neurons (Figure 3). This raises the possibility that the observed slow oscillation is an epiphenomenon of repetitive bursting. Inconsistent with this possibility, the frequency of bursting and the frequency of the slow oscillation were uncorrelated (Figure 4a). There was, however, a significant and positive correlation between the frequency of bursting and the amplitude of the slow oscillation ( $P_{\text {Low }}$, Figure $\left.4 \mathrm{~b}\right)$. Thus, bursting itself might be a 

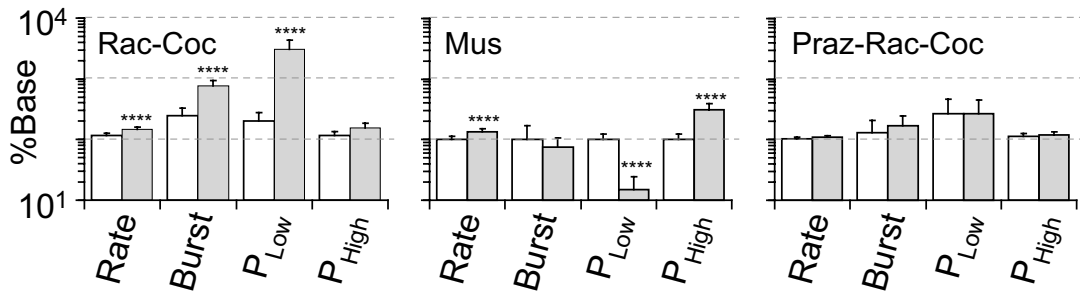

Figure 3 Summary bar graphs showing effects of cocaine and muscimol on firing properties of DA neurons. Four different parameters were measured: firing rate (spikes/I0 s), level of bursting (spikes in bursts/I 0 s), $P_{\text {Low }}$ (mean power between 0.5 and I.5 Hz), and $P_{\text {High }}$ (mean power between 3 and I $0 \mathrm{~Hz}$ ). Values are expressed as percent changes of baseline. Open and filled bars represent mean values before and after cocaine or muscimol, respectively. Left: cocaine $(n=15)$, given after raclopride, significantly increased firing rate, spikes in bursts, and $P_{\text {Low }}$, and had no effect on $P_{\text {High. }}$ Center: muscimol $(n=8)$ increased firing rate and $P_{\text {High, }}$ and decreased $P_{\text {Low. }}$. Similar effects were observed when muscimol was given after raclopride (not shown). Right: in prazosinpretreated rats (right, $n=6$ ), cocaine, given after raclopride, produced no significant effects on all four measures. Note that $Y$-axis are in log scale. ****** $p<0.00$ I compared to baseline (center chart) or values obtained after raclopride (left and right charts).
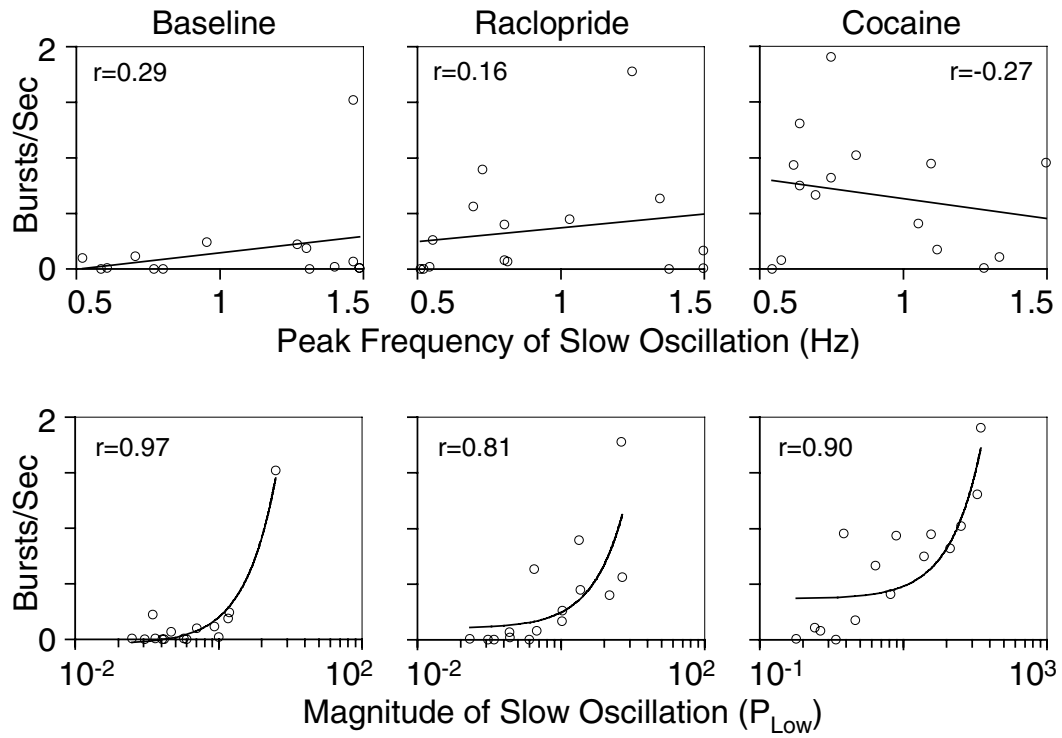

Figure 4 Relations between bursting and slow oscillations. There was no significant correlation between the frequency of bursting and the frequency of the slow oscillation (top). A significant correlation was observed, however, between the frequency of bursting and $P_{\text {Low }}$ (bottom).

phenomenon secondary to the slow oscillation, or the two measures reflect different aspects of the same process and/ or share some common mechanisms.

\section{Effects of D-Amphetamine, Methamphetamine, and Methylphenidate}

To test whether the effect of cocaine is shared by other psychostimulants, $\mathrm{D}$-amphetamine, methamphetamine, and methylphenidate were administered. All three psychostimulants inhibited DA neurons when given before raclopride (data not shown). When given after raclopride $(0.1-0.2 \mathrm{mg} /$ $\mathrm{kg}$ ), all three psychostimulants (D-amphetamine, $1 \mathrm{mg} / \mathrm{kg}$, $n=16$; methamphetamine, $1 \mathrm{mg} / \mathrm{kg}, n=6$; and methylphenidate, $1-2.5 \mathrm{mg} / \mathrm{kg}, n=15$ ) significantly increased $P_{\text {Low }}$ (Figure 5). Furthermore, the increase was reversed by prazosin in all cells tested (Figure $5 \mathrm{a}$ and $\mathrm{b}$ ).

\section{Effects of Nisoxetine}

Results with prazosin suggest that norepinephrine (NE) is a key mediator of the effect of psychostimulants. To test whether an increase in $\mathrm{NE}$ release alone can lead to an increase in the slow oscillation, the selective NE uptake blocker nisoxetine was administered before $(n=5)$ or after raclopride $(0.1 \mathrm{mg} / \mathrm{kg}, n=10)$. In both groups, nisoxetine $(10 \mathrm{mg} / \mathrm{kg})$ increased $P_{\text {Low }}$ (top charts in Figure 6). The effect was smaller, however, compared to the effect of psychostimulants. The increase induced by psychostimulants was approximately $44 \%$ (methylphenidate) to $738 \%$ (cocaine) higher than that induced by nisoxetine (Figures 3 and 5).

\section{Effects of L-Dopa}

Previous studies suggest that DA release in the VTA activates not only DA autoreceptors but also adrenergic $\alpha_{1}$ receptors (Grenhoff et al, 1995; Paladini et al, 2001) and a DAT-mediated inward current in DA neurons (Ingram et al, 2002). When DA autoreceptors are blocked, DA has been shown to excite DA neurons through the two non-DA receptor mechanisms. To test whether the two mechanisms are also responsible for the slow oscillation induced by psychostimulants, L-dopa was administered. L-Dopa, by increasing DA release, should activate both mechanisms. As observed previously (Bunney et al, 1973a), L-dopa (100 mg/ 

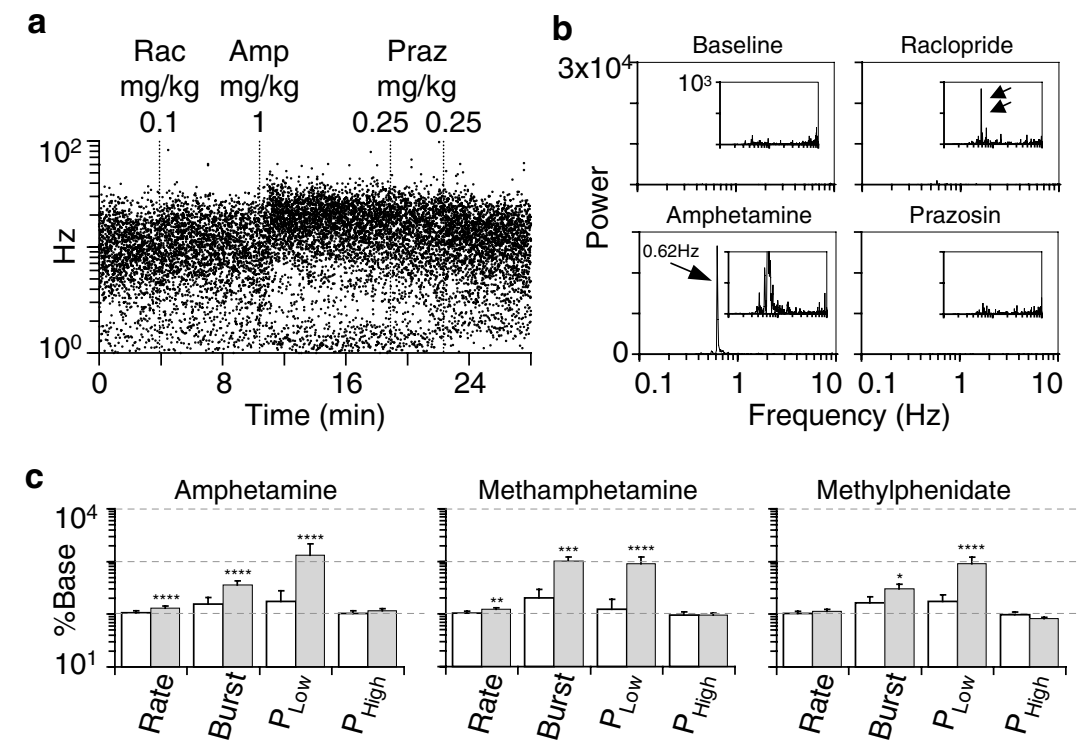

Figure 5 Effects of D-amphetamine, methamphetamine, and methylphenidate on DA neurons. (a) Plots of instantaneous firing rates showing that Damphetamine (Amp), given after raclopride (Rac), mimicked the effect of cocaine and increased the variation of ISIs. Prazosin (Praz) reversed the effect (see also spectra in b). (b) Power spectra of autocorrelograms showing an increase in slow oscillations induced by both raclopride (insets, double arrow) and Damphetamine, and the reversal of the increase by prazosin. Note that the effect of raclopride was much smaller than that of D-amphetamine (insets), and the effect of prazosin is more clearly shown here than in (a). Y-axis unit: (spikes $/ \mathrm{s})^{4} / \mathrm{Hz}$. (c) Summary bar graphs showing increases in $P_{\text {Low }}$ by $\mathrm{D}$-amphetamine (left, $n=16$ ), methamphetamine (center, $n=6$ ), and methylphenidate (right, $n=15$ ). Values are expressed as percent changes of baseline. Open and filled bars represent mean values before and after the injection of one of the psychostimulants, respectively. All three psychostimulants also increased firing rate and bursting. The effect of methylphenidate on firing rate, however, was statistically insignificant. $* p<0.05, * * p<0.01, * * * p<0.005, * * * * p<0.00$ I compared to values obtained after raclopride.

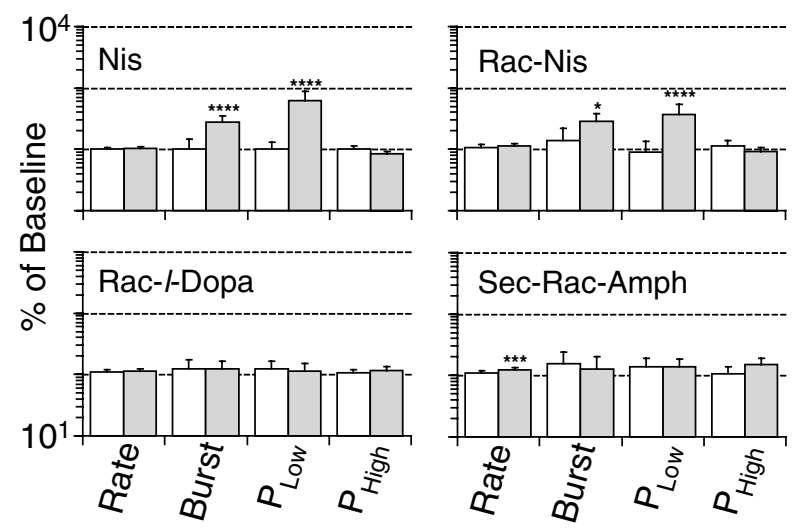

Figure 6 Effects of nisoxetine, L-dopa, and forebrain hemisections on DA neurons. The NE uptake blocker nisoxetine increased bursting and $P$ Low when given before (top left, $n=5$ ) or after raclopride (top right, $n=10$ ). L-Dopa produced no effect on all four measures when given after raclopride (bottom left, $n=13$ ). Following forebrain hemisections, Damphetamine, given after raclopride, also had no effect on bursting and

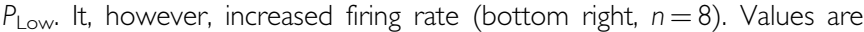
expressed as percent changes of baseline. Open and filled bars represent, respectively, mean values before and after the injection of nisoxetine, L-dopa, or D-amphetamine. $* p<0.05$, $* * * * 00.005$, $* * * * * p<0.00$ I compared to baseline (upper left chart) or values after raclopride (upper right and lower charts).

$\mathrm{kg}$ ) inhibited DA cell firing when given alone (from $4.8 \pm 0.5$ to $2.8 \pm 0.3$ spikes/s, $n=8, p<0.001$ ), and the inhibition was completely reversed by raclopride, confirming that L-dopa can cause DA release and activate DA autoreceptors. When given after raclopride $(0.1-0.2 \mathrm{mg} / \mathrm{kg})$, however, L-dopa produced $(100 \mathrm{mg} / \mathrm{kg})$ no significant effect on either firing rate or $P_{\text {Low }}(n=13$, lower left chart in Figure 6). Thus, VTA DA release and activation of the two non-DA receptor mechanisms may be necessary, but not enough for a drug to cause the slow oscillation in DA neurons.

\section{Effects of Forebrain Hemisection}

To test further whether the generation of the slow oscillation requires activation of more than just local mechanisms in the VTA, forebrain hemisections were made to interrupt forebrain inputs to DA neurons. In all cells tested, D-amphetamine $(1 \mathrm{mg} / \mathrm{kg})$, given after raclopride $(0.1-0.2 \mathrm{mg} / \mathrm{kg})$, failed to produce a significant effect on the slow oscillation $\left(P_{\text {Low }}\right)$, although in the same cells, it increased firing rate $(n=8$, lower right chart in Figure 6).

\section{DISCUSSION}

We have previously shown that D-amphetamine has two opposing effects on the firing activity of DA neurons: a DAmediated inhibition and a non-DA-mediated excitation (Shi et al, 2000b). Results of the present study show that the two effects are shared by all psychostimulants tested. Using spectral analysis, this study further shows that during psychostimulant-induced excitation, DA cells exhibit not only an increase in firing rate and bursting but also a slow rhythmic oscillation. The increase in firing is unlikely to be the direct cause of the slow oscillation since the $\mathrm{GABA}_{\mathrm{A}}$ agonist muscimol, which also increases DA cell firing, suppresses the slow oscillation. The nonpsychostimulant 
DA agonist L-dopa also fails to mimic the effect of psychostimulants. Further evidence suggests that the slow oscillation induced by psychostimulants requires the activation of $\alpha 1$ receptors and depends on intact forebrain inputs to DA neurons.

\section{Possible Mechanisms Underlying the Slow Oscillation Induced by Psychostimulants}

The blockade of the slow oscillation by the $\alpha 1$ antagonist prazosin and its mimic by the selective NE transporter blocker nisoxetine suggest that the effect is mediated, at least in part, by NE. The effect of nisoxetine, however, was less pronounced compared to that of psychostimulants. While this may be related to pharmacokinetic properties of different drugs, psychostimulants, by increasing release of both NE and DA, may induce more extensive $\alpha_{1}$ activation than nisoxetine. Previous studies suggest that DA may act as an NE agonist (Cornil et al, 2002). Unexpectedly, L-dopa, a precursor for both DA and NE, failed to mimic the effect of psychostimulants. One possibility is that L-dopa preferentially increases DA release. DA is synthesized in the cytoplasm and can be released via the DAT-mediated reverse transport when cytoplasmic DA concentration is high. NE, on the other hand, is synthesized within synaptic vesicles. Its release may therefore be less influenced by the cytoplasmic concentration of DA and more dependent on the firing rate of the cell. Studies have shown that L-dopa has no effect (Aoki et al, 1987) or decreases NE release (Dayan and Finberg, 2003).

The failure of L-dopa to mimic the effect of psychostimulants also supports the suggestion that DA release in the VTA is not enough to cause the slow oscillation. Previous studies suggest that VTA DA release activates not only DA autoreceptors but also $\alpha_{1}$ receptors (Grenhoff et al, 1995; Paladini et al, 2001) and the DAT-mediated inward current (Ingram et al, 2002). Thus, in the presence of DA receptor blockade, psychostimulants may act through the two nonDA receptor mechanisms to induce the slow oscillation. If this suggestion is correct, $\mathrm{L}-\mathrm{dopa}$, by increasing DA release, should mimic the effect. In this study, L-dopa was shown to mimic only the DA-mediated inhibition and not the slow oscillation, suggesting that DA release and activation of the two non-DA receptor mechanisms may be necessary, but not enough for a drug to induce the slow oscillation. The observation that disruption of forebrain inputs to DA neurons prevented $\mathrm{D}$-amphetamine from inducing the slow oscillation, but not the DA-mediated inhibition (Shi et al, 2000a) further supports the suggestion that psychostimulant-induced slow oscillation involves activation of more than just local mechanisms.

Results with forebrain hemisections also suggest that forebrain inputs may play a critical role in the slow oscillation induced by psychostimulants. Several forebrain areas are known to project directly to VTA DA neurons, including the prefrontal cortex (PFC), hippocampus, amygdala, nucleus accumbens, and ventral pallidum. The input from the PFC is of particularly interesting. Darracq et al (1998) have shown that part of DA release induced by D-amphetamine is DAT independent and can be blocked by prazosin locally injected into the PFC, suggesting that NE release and $\alpha_{1}$ receptor activation in the PFC may excite DA neurons, causing the DAT-independent DA release. Some PFC neurons also display a slow oscillatory activity at frequencies similar to that of the slow oscillation observed in VTA (Cowan et al, 1994; Lewis and O'Donnell, 2000). In preliminary experiments, transections immediately posterior to the PFC reduced the effect of D-amphetamine on the slow oscillations. Taken together, these results suggest that the PFC might be an important component in the neuronal circuitry that mediates the slow oscillation in DA neurons.

\section{Potential Significance of the Slow Oscillation}

The reinforcing effects of psychostimulants have been largely attributed to their ability to increase DA release. Both L-dopa and muscimol also increase DA release. Neither, however, has significant reinforcing efficacies (Patkina and Lapin, 1976; Poncelet et al, 1983; Xi and Stein, 1998), suggesting that not all drugs capable of increasing DA release are reinforcing. The slow conversion of L-dopa to DA and the $\mathrm{GABA}_{\mathrm{A}}$ action of muscimol may explain the lack of reinforcing efficacies of the two drugs. Results of this study raise another possibility. The reinforcing properties of psychostimulants may depend on both DA release and activation of the network underlying the slow oscillation. Thus, the inability of L-dopa and muscimol to produce the latter effect may contribute to the lack of reinforcing properties of the two drugs.

Oscillatory firing could affect both DA release from DA terminals and information processing in DA soma and dendrites. Gonon (1988) showed that a rhythmic, lowfrequency $(1 \mathrm{~Hz})$ burst stimulation is up to six times more potent than evenly spaced stimulation in evoking DA release. Oscillations in firing may also lead to an oscillatory release. Grace (2000) suggests that phasic and tonic DA release may serve different functions. Oscillatory release also provides a means for DA terminals to differentially interact other inputs to the same target neurons. Inputs that coincide with the oscillatory activity of DA cells may be affected more by DA than those that do not. At the cell body area, oscillations may enable a neuron to act as a coincidence detector and to become more sensitive to the precise timing of synaptic inputs (Volgushev et al, 1998). In cells with oscillations, discharges evoked by synaptic inputs has been shown to be phase locked to the oscillation cycle (Volgushev et al, 1998). These properties, together with the observation that precise synchronization is often associated with oscillatory responses, suggest that oscillations are instrumental for synchrony between spatially distributed neurons.

It should be pointed out that the slow oscillation induced by psychostimulants was observed when DA-mediated feedback inhibition was blocked by raclopride. In rats without raclopride, psychostimulants inhibited DA cells. Accompanied with this inhibition, $P_{\text {Low }}$ was either unchanged or decreased (data not shown), suggesting that the DA-mediated inhibition prevents the expression of the slow oscillation. However, when a cell stops firing or fires at a low rate, the slow oscillation may occur mainly at subthreshold levels, expressed as changes in the membrane potential and not fully reflected in firing rate. Owing to this, it may not be detected by a technique relying on analysis of spikes. Thus, a direct measurement of the membrane 
potential will be required to provide more convincing evidence for whether or not the activity is present when D2-like receptors are not blocked.

In adult rats anesthetized with chloral hydrate, the DAmediated inhibition induced by a psychostimulant is more dominant than the excitatory effect induced by the same drug. However, as cited in the introduction, the inhibitory effect may weaken and the excitatory effect may become more dominant under certain conditions (Kamata and Rebec, 1984; Trent et al, 1991; Jones et al, 1999). It would be interesting to determine whether under these conditions, a psychostimulant can induce the slow oscillation without prior D2 blockade.

Regardless of whether the slow oscillation is expressed, activation of the network responsible for the activity and corresponding receptors on DA neurons may have delayed and possibly long-lasting effects. A previous study shows that a single injection of cocaine induces long-term potentiation of glutamate synapses on DA neurons (Ungless et al, 2001). It would be interesting to determine whether these synapses are part of the network mediating the slow oscillation, and whether the reported long-term potentiation is due to repeated, low-frequency activation of these synapses by cocaine.

\section{ACKNOWLEDGEMENTS}

We thank Drs BS Bunney, JD Elsworth, BA Morrow, and RH Roth for critically reading the manuscript, and Dr Y-X Cao for suggestions on data analysis.

\section{REFERENCES}

Aoki S, Inukai K, Sakurai M, Koshikawa N, Kobayashi M (1987). Monitoring of dopamine metabolism by in vivo voltammetry and high performance liquid chromatography in L-dopa-treated rats. Jpn J Pharmacol 43: 98-102.

Auclair A, Cotecchia S, Glowinski J, Tassin JP (2002). D-amphetamine fails to increase extracellular dopamine levels in mice lacking alpha $1 \mathrm{~b}$-adrenergic receptors: relationship between functional and nonfunctional dopamine release. J Neurosci 22: 9150-9154.

Bunney BS, Aghajanian GK, Roth RH (1973a). Comparison of effects of L-dopa, amphetamine and apomorphine on firing rate of rat dopaminergic neurones. Nat New Biol 245: 123-125.

Bunney BS, Walters JR, Roth RH, Aghajanian GK (1973b). Dopaminergic neurons: effect of antipsychotic drugs and amphetamine on single cell activity. J Pharmacol Exp Ther 185: 560-571.

Carboni E, Spielewoy C, Vacca C, Nosten-Bertrand M, Giros B, Di Chiara G (2001). Cocaine and amphetamine increase extracellular dopamine in the nucleus accumbens of mice lacking the dopamine transporter gene. J Neurosci 21: RC141-RC144.

Cornil CA, Balthazart J, Motte P, Massotte L, Seutin V (2002). Dopamine activates noradrenergic receptors in the preoptic area. J Neurosci 22: 9320-9330.

Cowan RL, Sesack SR, Van Bockstaele EJ, Branchereau P, Chain J, Pickel VM (1994). Analysis of synaptic inputs and targets of physiologically characterized neurons in rat frontal cortex: combined in vivo intracellular recording and immunolabeling. Synapse 17: 101-114.

Darracq L, Blanc G, Glowinski J, Tassin JP (1998). Importance of the noradrenaline-dopamine coupling in the locomotor activating effects of D-amphetamine. J Neurosci 18: 2729-2739.
Dayan L, Finberg JP (2003). L-dopa increases noradrenaline turnover in central and peripheral nervous systems. Neuropharmacology 45: 524-533.

Einhorn LC, Johansen PA, White FJ (1988). Electrophysiological effects of cocaine in the mesoaccumbens dopamine system: studies in the ventral tegmental area. J Neurosci 8: 100-112.

Ellinwood Jr EH, Lee TH (1983). Effect of continuous systemic infusion of D-amphetamine on the sensitivity of nigral dopamine cells to apomorphine inhibition of firing rates. Brain Res 273: 379-383.

Gonon FG (1988). Nonlinear relationship between impulse flow and dopamine released by rat midbrain dopaminergic neurons as studied by in vivo electrochemistry. Neuroscience 24: 19-28.

Grace AA (2000). The tonic/phasic model of dopamine system regulation and its implications for understanding alcohol and psychostimulant craving. Addiction 95(Suppl 2): S119-S128.

Grace AA, Bunney BS (1979). Paradoxical GABA excitation of nigral dopaminergic cells: indirect mediation through reticulata inhibitory neurons. Eur J Pharmacol 59: 211-218.

Grace AA, Bunney BS (1983). Intracellular and extracellular electrophysiology of nigral dopaminergic neurons - 1. Identification and characterization. Neuroscience 10: 301-315.

Grace AA, Bunney BS (1984). The control of firing pattern in nigral dopamine neurons: burst firing. J Neurosci 4: 2877-2890.

Grenhoff J, North RA, Johnson SW (1995). Alpha 1-adrenergic effects on dopamine neurons recorded intracellularly in the rat midbrain slice. Eur J Neurosci 7: 1707-1713.

Henry DJ, Greene MA, White FJ (1989). Electrophysiological effects of cocaine in the mesoaccumbens dopamine system: repeated administration. J Pharmacol Exp Ther 251: 833-839.

Ingram SL, Prasad BM, Amara SG (2002). Dopamine transportermediated conductances increase excitability of midbrain dopamine neurons. Nat Neurosci 5: 971-978.

Jones SR, Gainetdinov RR, Hu XT, Cooper DC, Wightman RM, White FJ et al (1999). Loss of autoreceptor functions in mice lacking the dopamine transporter. Nat Neurosci 2: 649-655.

Kamata K, Rebec GV (1983). Dopaminergic and neostriatal neurons: dose-dependent changes in sensitivity to amphetamine following long-term treatment. Neuropharmacology 22: 1377-1382.

Kamata K, Rebec GV (1984). Long-term amphetamine treatment attenuates or reverses the depression of neuronal activity produced by dopamine agonists in the ventral tegmental area. Life Sci 34: 2419-2427.

Lewis BL, O’Donnell P (2000). Ventral tegmental area afferents to the prefrontal cortex maintain membrane potential 'up' states in pyramidal neurons via $\mathrm{D}(1)$ dopamine receptors. Cereb Cortex 10: $1168-1175$.

Paladini CA, Fiorillo CD, Morikawa H, Williams JT (2001). Amphetamine selectively blocks inhibitory glutamate transmission in dopamine neurons. Nat Neurosci 4: 275-281.

Patkina NA, Lapin IP (1976). Effects of catecholaminergic drugs on systems of reward and punishment in experiments on cats. Pharmacol Biochem Behav 5: 247-252.

Poncelet M, Chermat R, Soubrie P, Simon P (1983). The progressive ratio schedule as a model for studying the psychomotor stimulant activity of drugs in the rat. Psychopharmacology (Berl) 80: 184-189.

Shi WX, Pun CL, Yan Z (2003). Psychostimulants induce slow oscillations of dopamine neurons. ACNP 42nd Annual Meeting San Juan, Puerto Rico.

Shi WX, Pun CL, Smith PL, Bunney BS (2000a). Endogenous DA-mediated feedback inhibition of DA neurons: involvement of both $\mathrm{D}(1)$ - and $\mathrm{D}(2)$-like receptors. Synapse 35: 111-119.

Shi WX, Pun CL, Zhang XX, Jones MD, Bunney BS (2000b). Dual effects of $\mathrm{D}$-amphetamine on dopamine neurons mediated by dopamine and nondopamine receptors. J Neurosci 20: 3504-3511. 
Trent F, Nakamura S, Tepper JM (1991). Amphetamine exerts anomalous effects on dopaminergic neurons in neonatal rats in vivo. Eur J Pharmacol 204: 265-272.

Ungless MA, Whistler JL, Malenka RC, Bonci A (2001). Single cocaine exposure in vivo induces long-term potentiation in dopamine neurons. Nature 411: 583-587.

Volgushev M, Chistiakova M, Singer W (1998). Modification of discharge patterns of neocortical neurons by induced oscillations of the membrane potential. Neuroscience 83: $15-25$.

Walters JR, Lakoski JM (1978). Effect of muscimol on single unit activity of substantia nigra dopamine neurons. Eur J Pharmacol 47: 469-471.
Waszczak BL, Walters JR (1980). Intravenous GABA agonist administration stimulates firing of A10 dopaminergic neurons. Eur J Pharmacol 66: 141-144.

White FJ, Wang RY (1984). Electrophysiological evidence for A10 dopamine autoreceptor subsensitivity following chronic D-amphetamine treatment. Brain Res 309: 283-292.

Wolf ME, White FJ, Nassar R, Brooderson RJ, Khansa MR (1993). Differential development of autoreceptor subsensitivity and enhanced dopamine release during amphetamine sensitization. J Pharmacol Exp Ther 264: 249-255.

Xi ZX, Stein EA (1998). Nucleus accumbens dopamine release modulation by mesolimbic GABAA receptors-an in vivo electrochemical study. Brain Res 798: 156-165. 